Vol. 1 No. 1, Feb 2021, hlm. $71-78$

DOI: https://doi.org/10.33330/.v1i1.1047

Available online at https://jurnal.stmikroyal.ac.id/index.php/jutsi

\title{
IMPLEMENTASI CUSTOMER RELATIONSHIP MANAGEMENT UNTUK PENINGKATAN KUALITAS PELAYANAN PADA KLINIK DINDA BERBASIS WEB
}

\author{
Ade Nova Alvionnita Mrp ${ }^{1}$, Ada Udi Firmansyah ${ }^{2 *}$, Dewi Maharani ${ }^{3}$ \\ ${ }^{1}$ Mahasiswa Prodi Sistem Informasi, STMIK Royal \\ ${ }^{2}$ Prodi Sistem Informasi, STMIK Royal \\ ${ }^{3}$ Prodi Manajemen Informatika, STMIK Royal \\ *email: audi.ciyanda@gmail.com
}

\begin{abstract}
Dinda Clinic is a clinic that serves the health sector. The problems that arise at Dinda's clinic are manual registration, no doctor's schedule, and no forum for criticism and suggestions. Dinda Clinic needs a Website-based Customer Relationship Management (CRM) application to overcome these problems, the CRM applications uses the PHP programming languages and uses the MySQL database, before CRM was designed, the authors conducted data analysis first to collect the required data dan information. After being analyzed, the implementation is designed and can produce a website-based CRM programs. The results obtained in this studis are by implementing a website-based CRM application in the clinic, so that it can make it easier for the clinic to manage all data managements processes, so that there is good interaction between the patient and the Dinda Clinic with two-way communication.
\end{abstract}

Keywords: CRM, Quality of Service, Clinic, MYSQL, PHP

\begin{abstract}
Abstrak: Klinik Dinda ialah klinik yang melayani dibidang kesehatan. Masalah yang muncul pada klinik Dinda adalah pendaftaran yang masih manual, tidak adanya penjadwalan dokter serta tidak adanya wadah kritik dan saran. Klinik Dinda memerlukan suatu aplikasi Customer Relationship Management (CRM) berbasis Website untuk mengatasi permasalahan tersebut, aplikasi CRM memakai bahasa pemrograman PHP dan menggunakan database MySQL, sebelum CRM dirancang, penulis melakukan analisis data terlebih dahulu buat mengumpulkan data dan informasi yang dibutuhkan. Setelah dianalisis lalu pelaksanaan tersebut dirancang lalu dapat menghasilkan sebuah program CRM berbasis website. Hasil yang didapatkan dari penelitian ini yaitu untuk menerapkan aplikasi CRM berbasis website di klinik, sehingga dapat memudahkan pihak klinik dalam mengelola proses pengelolaan data, sehingga terjalin interaksi yang baik antara pihak pasien dengan pihak Klinik Dinda dengan adanya komunikasi dua arah.
\end{abstract}

Kata kunci : CRM, Kualitas Pelayanan, Klinik, MYSQL, PHP 
Vol. 1 No. 1, Feb 2021, hlm. $71-78$

DOI: https://doi.org/10.33330/.v1i1.1047

Available online at https://jurnal.stmikroyal.ac.id/index.php/jutsi

\section{PENDAHULUAN}

CRM adalah strategi yang digunakan perusahaan untuk membentuk interaksi yang baik dengan pelanggan (customer) sehingga dapat memberikan kontribusi dan keuntungan jangka panjang bagi perusahaan. Setiap perusahaan perlu memahami rantai nilai CRM agar mampu memenuhi setiap kebutuhan pelanggan. Pelanggan tidak hanya merasa puas namun tetap menjadi pelanggan yang setia. Melalui CRM, perusahaan akan menguasai metode manajemen agar dapat mempertahankan pelangganya, mengakuisisi pelanggan baru dan berbagi pelanggan [1].

Kualitas pelayanan menjadi ukuran seberapa mengagumkan tingkat layanan yang diberikan bisa sesuai dengan ekspektasi pelanggan. Berdasarkan definisi ini, kualitas jasa dapat diwujudkan melalui pemenuhan kebutuhan serta keinginan pelanggan dan ketepatan penyampaiannya untuk mengimbangi harapan pelanggan [2].

Klinik Dinda adalah klinik rawat jalan dan juga rawat inap yang didedikasikan untuk masyarakat umum serta dilengkapi dengan layanan kesehatan yang membantu dalam meningkatan kesehatan masyarakat. Untuk memaksimalkan kualitas dan pelayanan pasien. Permasalahan terkait pelayanan pasien serta sistem yang terdapat pada Klinik Dinda, dalam pengelolaan data pasien Klinik Dinda masih melakukannya dengan manual yaitu menuliskan nama-nama pasien yang sudah mendaftar kedalam buku besar untuk pasien.

Untuk mengatasi permasalahan tersebut diatas, maka penulis ingin membuat sebuah sistem aplikasi CRM yang dapat menguatkan suatu interaksi yang baik dengan adanya komunikasi dua arah antara pihak Klinik Dinda dengan pihak pasien untuk melahirkan kepercayaan pasien dalam menggunakan pelayanan jasa kesehatan di Klinik Dinda. Sehingga tingkat kepuasan pasien meningkat dengan adanya pelayanan yang diberikan pada klinik Dinda.

\section{METODE}

Metode penelitian yang digunakan merupakan jenis metode penelitian kualitatif dimana metode jenis ini mengolah data yang tidak berupa rangkaian angka, melainkan berwujud kata-kata [3]. Metode yang digunakan dalam penelitian ini ialah penelitian kualitatif. Data kualitatif merupakan data yang teknik pengolahannya dilakukan dengan melakukan penelitian Observasi atau pengamatan yaitu pengumpulan data dengan cara datang langsung ke klinik Dinda Sentang dan melakukan wawancara langsung kepada perawat di Klinik Dinda.

\section{HASIL DAN PEMBAHASAN}

Implementasi merupakan suatu aplikasi yang telah disusun secara matang dan terperinci. Implementasi umumnya dilakukan selesai perencanaan sistem dibuat. Implementasi merupakan kegiatan, aksi, tindakan atau adanya prosedur suatu sistem, implementasi bukan sekedar kegiatan, akan tetapi suatu aktivitas berkala dan untuk mencapai tujuan aktivitas [4]. Pengujian sistem merupakan pengujian program software. Black-Box Testing adalah Teknik pengujian software yang berfokus dalam spesifikasi 
Vol. 1 No. 1, Feb 2021, hlm. $71-78$

DOI: https://doi.org/10.33330/.v1i1.1047

Available online at https://jurnal.stmikroyal.ac.id/index.php/jutsi

fungsional dari perangkat lunak. Blackbox Testing bekerja mengabaikan struktur kontrol sebagai akibatnya difokuskan pada informasi domain [5]. Tahap pengujian sistem ini akan menggunakan black box testing apakah program sudah berfungsi atau belum serta memberikan gambaran terhadap fitur-fitur yang tersedia dalam website CRM pada Klinik Dinda.

Setelah melalui tahap uji coba sistem, Implementasi halaman utama sistem CRM ditampilkan saat pengguna mengakses website pertama kali. Antarmuka ini menampilkan menu profil, contack, konsultasi, registrasi pasien, login pasien dan login admin. Berikut tampilan awal dari sistem.

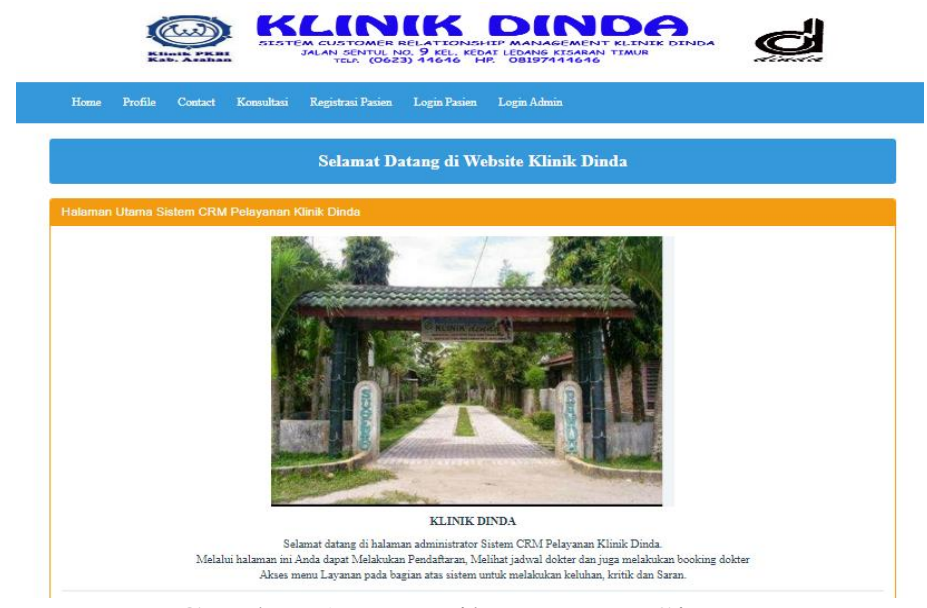

Gambar 1. Tampilan Utama Sistem

Selanjutnya melakukan Registrasi bagi pasien yang ingin login dan mengakses sistemnya. Berikut tampilan halaman registrasi pasien Klinik Dinda.

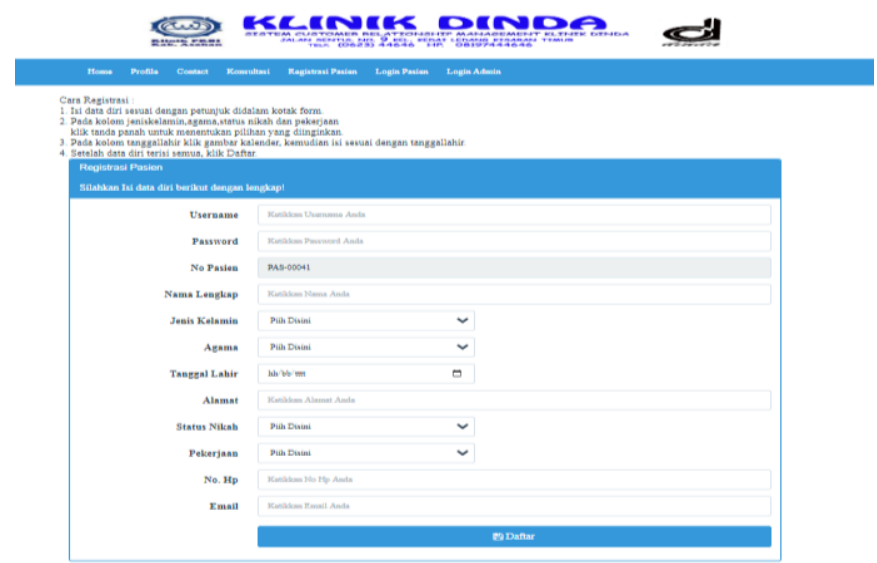

Gambar 2. Tampilan Registrasi Pasien

Pertama kali pasien masuk sistem setelah login, maka halaman utama unuk pasien akan langsung tampil, pasien dapat mengklik menu-menu yang ada disistem. Menu yang terdapat di sistem terdiri dari menu home, konsultasi, jadwal dokter, booking dokter, kritik dan saran, serta logout. Berikut tampilan halaman utama pasien pada sistem Klinik Dinda. 
Vol. 1 No. 1, Feb 2021, hlm. $71-78$

DOI: https://doi.org/10.33330/.v1i1.1047

Available online at https://jurnal.stmikroyal.ac.id/index.php/jutsi

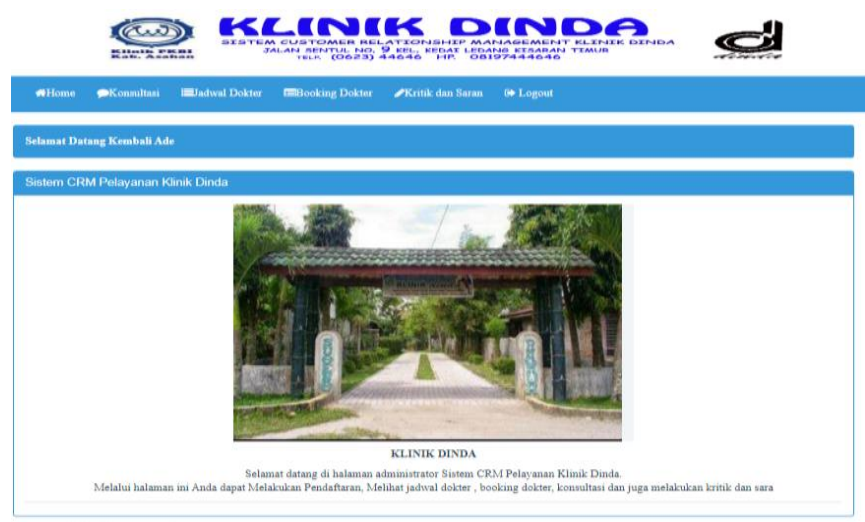

Gambar 3. Tampilan Halaman Utama Pasien

Pasien yang hanya ingin menanyakan keluhan dan tidak bisa datang langsung ke klinik dapat memanfaatkan menu konsultasi, dimenu konsultasi pasien bisa berkirim pesan pada admin. Maka admin akan memberikan saran obat dan masukan terhadap keluhan yang dialami oleh pasien. Berikut tampilan form konsultasi pada sistem Klinik Dinda.

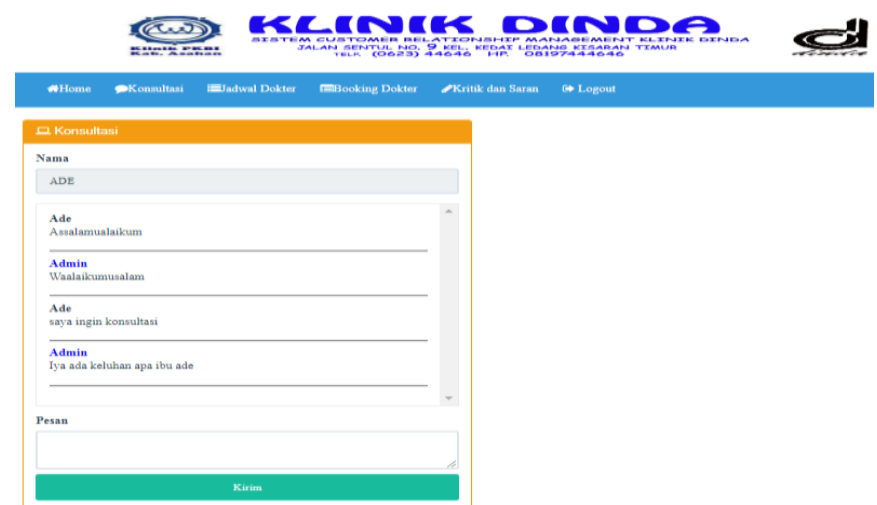

Gambar 4. Tampilan Konsultasi

Pada halaman ini pasien yang ingin memberikan saran atau masukan pada Klinik Dinda agar pelayanan pada Klinik Dinda dapat lebih baik lagi, serta kritikan terhadap pelayanan Klinik Dinda. Berikut tampilan halaman kritik dan saran pada sistem Klinik Dinda.

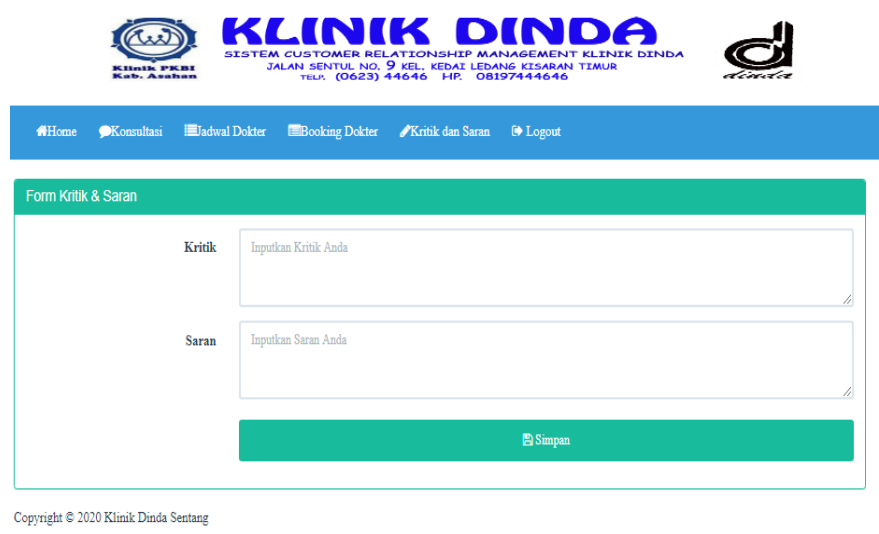

Gambar 5. Tampilan Kritik dan Saran 
Vol. 1 No. 1, Feb 2021, hlm. $71-78$

DOI: https://doi.org/10.33330/.v1i1.1047

Available online at https://jurnal.stmikroyal.ac.id/index.php/jutsi

Selanjutnya dalam halaman utama dokter terdapat beberapa menu yang ditampilkan, menu-menu yang ditampilkan yaitu: home, data dokter, rekam medis, data booking dan logout. Dengan adanya menu ini dokter dapat melihat pasien yang sudah membooking dan menginputkan hasil rekam medis pasien kesistem.

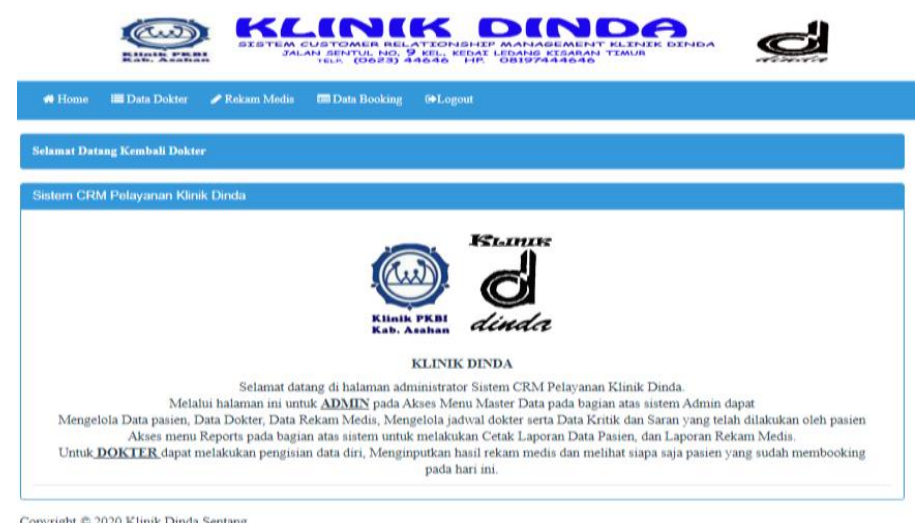

Gambar 6. Tampilan Halaman Utama Dokter

Dalam tampilan halaman rekam medis. Dokter dapat menambah hasil rekam medis yang didapat pada saat dokter selesai memeriksa pasien. Berikut tampilan form rekam medis pada sistem Klinik Dinda.

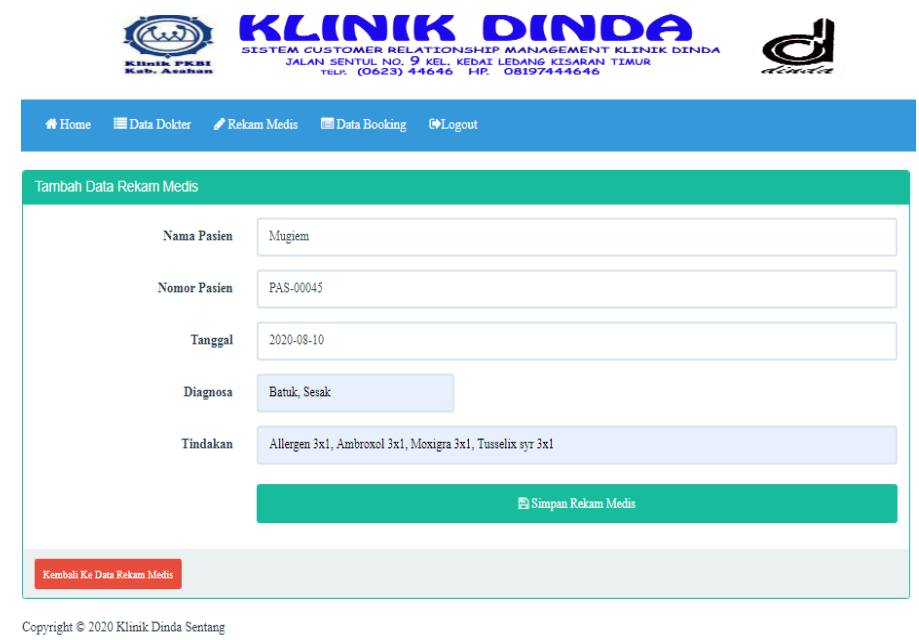

Gambar 7. Tampilan Rekam Medis

Dalam halaman utama admin terdiri dari beberapa menu, menu-menu yang ditampilkan yaitu; home, konsultasi, menu Master data terdiri atas, data pasien, data dokter, jadwal dokter, data booking, serta kritik dan saran. Serta menu laporan pasien , laporan rekam medis, user juga logout. Berikut tampilan halaman utama admin pada Klinik Dinda. 
Vol. 1 No. 1, Feb 2021, hlm. $71-78$

DOI: https://doi.org/10.33330/.v1i1.1047

Available online at https://jurnal.stmikroyal.ac.id/index.php/jutsi

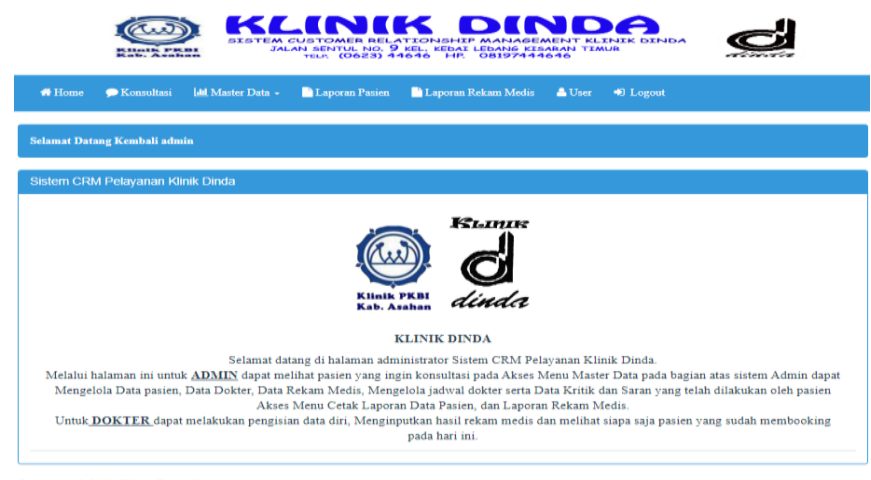

Gambar 8. Tampilan Halaman Utama Admin

Pada tampilan halaman konsultasi merupakan halaman yang ada pada admin. Admin dapat melihat siapa saja yang ingin konsultasi dan admin juga yang akan membalas konsultasi dari pasien. Berikut tampilan data konsultasi pada sistem Klinik Dinda.



Gambar 9. Tampilan Mengelola Konsultasi

Pada tampilan halaman data kritik dan saran merupakan halaman yang ada pada admin. Admin dapat melihat kritik dan saran yang telah diinputkan oleh pasien, admin juga bisa menghapus data kritik dan saran tersebut. Berikut tampilan data kritik dan saran disistem Klinik Dinda.

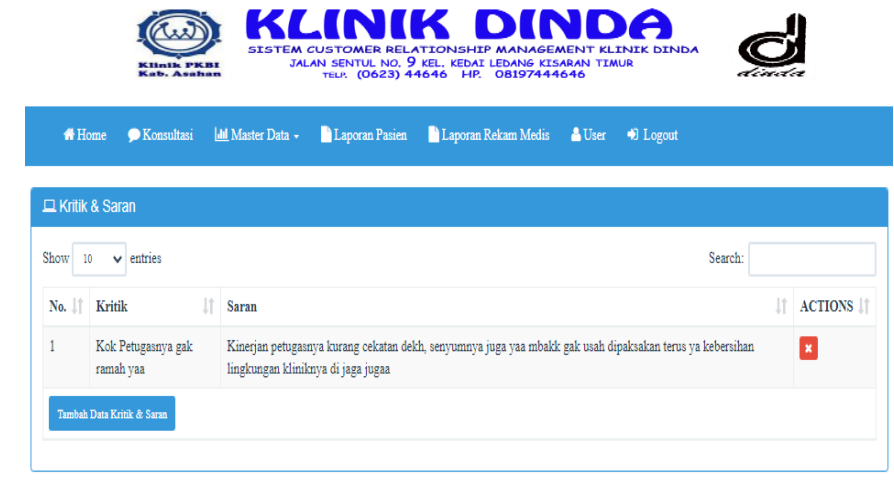

Gambar 10. Tampilan Kritik dan Saran

Pada tampilan halaman laporan data pasien merupakan halaman yang ada pada admin. Admin dapat mencetak satu data atau semua data pasien yanng ada. Berikut tampilan laporan data pasien pada sistem Klinik Dinda. 
Vol. 1 No. 1, Feb 2021, hlm. $71-78$

DOI: https://doi.org/10.33330/.v1i1.1047

Available online at https://jurnal.stmikroyal.ac.id/index.php/jutsi

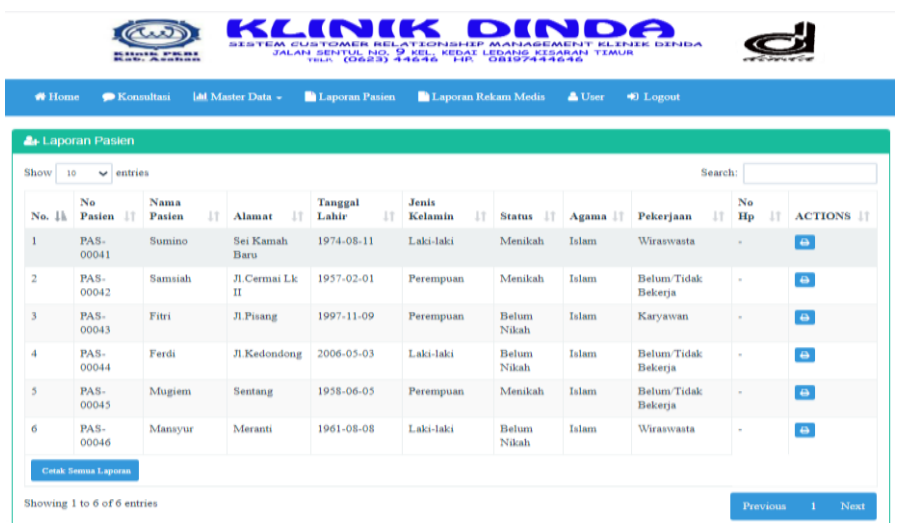

Gambar 11. Tampilan Laporan pasien

Pada tampilan halaman laporan data rekam medis pasien merupakan halaman yang ada pada admin. Admin dapat mencetak satu data atau semua data hasil rekam medis yang ada. Berikut tampilan laporan rekam medis pada sistem Klinik Dinda.

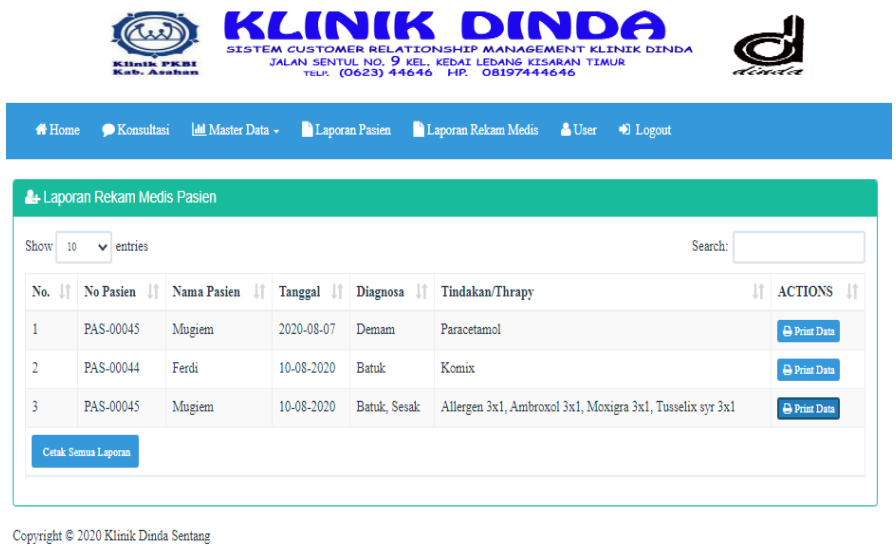

Gambar 12. Tampilan Laporan Rekam Medis

Pada tampilan halaman cetak laporan data pasien dan data hasil rekam medis merupakan halaman output yang ada pada admin. Laporan ini nantinya akan diberikan kepada pasien. Berikut tampilan cetak laporan data pasien dan hasil rekam medis pada sistem Klinik Dinda.

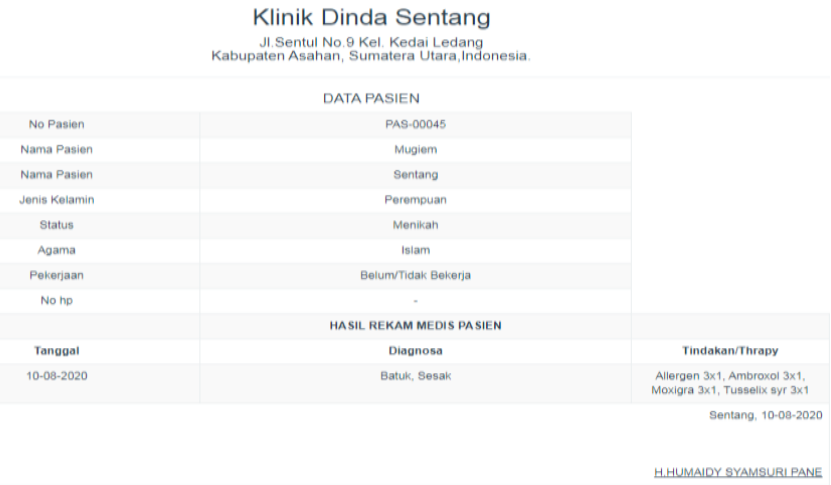

Gambar 13. Tampilan Cetak Laporan Rekam Medis 
Vol. 1 No. 1, Feb 2021, hlm. $71-78$

DOI: https://doi.org/10.33330/.v1i1.1047

Available online at https://jurnal.stmikroyal.ac.id/index.php/jutsi

\section{SIMPULAN}

Berdasarkan pembahasan yang diuraikan pada bab-bab sebelumnya, maka penulis dapat menarik beberapa kesimpulan sebagai berikut: penerapan CRM pada Sistem Pelayanan pada Klinik Dinda dapat dijadikan sebagai solusi bisnis terbaru untuk Klinik Dinda dalam meningkatkan kualitas pelayanan kepada pasien. Dengan adanya fitur Penjadwal dokter di website yang up to date. Sehingga Pasien dapat mengetahui kehadiran dokter dengan jelas tanpa harus datang langsung ke klinik.

Dengan adanya fitur Pendaftaran Online Pasien dan Booking dokter di website. Pasien tidak harus mengantri dan tidak menunggu lama saat pendaftaran pasien dan bertemu dengan dokter. Dengan adanya fitur Konsultasi, pasien yang memiliki keluhan namun tidak dapat keluar rumah dikarenakan keadaan. Dapat memanfaatkan fitur konsultasi yang ada di website untuk mengirim pesan keluhan yang dialami oleh pasien. Sistem CRM ini terdapat fitur halaman saran dan kritik untuk semua masukan dan keluhan dari pasien apabila ada pelayanan yang dianggap kurang memuaskan.

\section{DAFTAR PUSTAKA}

[1] Y. B. Utomo, W. W. Winarno, and A. Amborowati, "PERANCANGAN CUSTOMER RELATIONSHIP MANAGEMENT PADA KLINIK ( Studi Kasus : Klinik Pratama Nusa Medika Meritjan )," vol. 10, no. 1, pp. 57-68, 2016.

[2] H. Irawan, A. F. Indriani, S. Informasi, F. T. Informasi, and U. B. Luhur, "Analisa Dan Perancangan Electronic Customer Relationship Management ( ECrm ) Dalam Meningkatkan Loyalitas Alumni," Event (London), pp. 87-94, 2013.

[3] A. Fauzi and E. Harli, "Peningkatan Kualitas Pelayanan Melalui CRM dengan Metode RAD," J. RESTI (Rekayasa Sist. dan Teknol. Informasi), vol. 1, no. 1, p. 76, 2017, doi: 10.29207/resti.v1i1.16.

[4] M. P. Babar and M. Saitakela, "Implementasi Customer Relationship Management (Crm) Pada Klinik Valerie Beauty," JITU J. Inform. Technol. Commun., vol. 3, no. 1, pp. 58-63, 2019, doi: 10.36596/jitu.v3i1.74.

[5] T. S. Jaya, "Pengujian Aplikasi dengan Metode Blackbox Testing Boundary Value Analysis (StudiJaya, T. S. (2018). Pengujian Aplikasi dengan Metode Blackbox Testing Boundary Value Analysis (Studi Kasus: Kantor Digital Politeknik Negeri Lampung). Jurnal Informatika Penge," J. Inform. Pengemb. IT, vol. 3, no. 2, pp. 45-46, 2018, [Online]. Available: http://www.ejournal.poltektegal.ac.id/index.php/informatika/article/view/647/640 